\title{
Viruria of Human BK Virus and John Cunningham Virus among Renal Transplant Recipients and Healthy Control in Southeast of Caspian Sea
}

\author{
Fereshteh Safaei $^{a} \quad$ Alireza Mohebbia, b, c Mina Hassanpour ${ }^{a, b}$ \\ Hadi Razavi Nikoo ${ }^{\text {b, } d}$ Alijan Tabarraei ${ }^{b, d}$ \\ astudent Research Committee, School of Medicine, Golestan University of Medical Sciences, Gorgan, Iran; \\ ${ }^{b}$ Department of Microbiology, School of Medicine, Golestan University of Medical Sciences, Gorgan, Iran; \\ 'Stem Cell Research Center, School of Medicine, Golestan University of Medical Sciences, Gorgan, Iran; \\ dInfectious diseases research center, Golestan University of Medical Sciences, Gorgan, Iran
}

\section{Keywords}

Renal transplant recipient · BK virus · John Cunningham virus - Genotyping

\begin{abstract}
Background: Members of the Polyomaviridae family, BK virus (BKV), and John Cunningham virus (JCV) are linked to polyomavirus-associated nephropathy-associated transplant rejection in immunodeficient patients. Objective: The aim of the study was to evaluate the prevalence of BKV and $J C V$ in immunocompetent individuals in the north of Iran. Methods: Ninety-one urine samples were obtained from renal transplant recipients with a mean age of $39.78 \pm 11.19$ years. A healthy control group of 65 volunteers with an average age of $40.32 \pm 10.7$ years also contributed. After DNA extraction, positive cases were detected through PCR. Genotyping was done by alignment and phylogenetic tree construction of the VP1 region against all known JCV and BKV genotypes. Results: The prevalence of BKV and JCV was 15.38 and $19.78 \%$, respectively. JCV was detected in $7.69 \%$ of the control group. The prevalence of the BKV between the case and control groups was significant $(p<0.0001)$.
\end{abstract}

There was no significant association between BKV and JCV and duration of dialysis $(p>0.05)$. Overall, $62.16 \%$ of JCV cases were genotype I. Besides, genotype II was dominant within patients with BKV-positive patients. Discussion: The results obtained here show a relatively lower prevalence of BKV and JCV in immunocompromised renal transplant receivers and healthy control than those reported from other areas in Iran. JCV genotyping was evaluated for the first time in Iran. Genotype I for JCV and genotype II for BKV were dominant genotypes in the north of Iran.

() 2021 S. Karger AG, Basel

\section{Introduction}

Kidney transplantation is the final treatment option for patients with ESRD. In this regard, major concerns are related to graft rejection due to immunity and a variety of viral infections. John Cunningham virus (JCV) and BK virus (BKV) are 2 important viruses within the family Polyomaviridae, which are involved in renal transplant rejection [1].

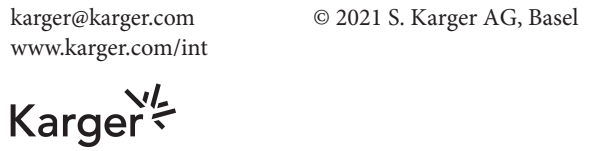

Alijan Tabarraei 
Today, it is known that $\sim 80 \%$ of healthy adults are seropositive for Polyomaviridae, and they may become reactive in immunodeficient conditions $[2,3]$. The use of immunosuppressive drugs in a transplant recipient leads to an increased incidence of BKV and JCV diseases. Polyomavirus reactivation in kidney and bone marrow transplant recipients is due to the use of immunosuppressive drugs and because of immune deficiency. Therefore, investigation of the incidence of these viruses in the transplant recipients is necessary to prevent reactivation of the virus and to prevent transplantation termination. The genomic prevalence of BKV and JCV in urine specimens of kidney recipients is 46.7 and $23.3 \%$, respectively, and 13.3 and $24.5 \%$, respectively, in healthy subjects [4].

$\mathrm{BKV}$ is a human polyomavirus first isolated from the urine of an immunocompromised renal transplant patient by Gardner et al. [5] in 1971. BKV may reactivate after renal transplantation and lead to nephropathy-associated rejection of the renal graft. In the previous work on biopsy samples from renal transplant recipients, BKV was found in $13.1 \%$ of clinical samples in Iran [6]. SamarbasfZadeh et al. [7] have shown a 3-fold increase of BKV reactivation after 4 mounts of renal transplantation. BKV is divided into several serotypes. In a small population study, Motazakker et al. [8] have shown that the BKV serotype I is dominated in Iranian Turkish renal transplant recipients. In another study in Iran with more participants, it was found that serotype I of BKV with $94.11 \%$ frequency was more prevalent than serotype IV with $5.89 \%$ [9].

JCV is an opportunistic pathogen in the human population that generally infects children and can persist in the renal tissue and bone marrow [10]. The virus can lead to progressive multifocal leukoencephalopathy in patients infected with human immunodeficiency virus [11]. The prevalence of the JCV was estimated to be $38.3-40 \%$ in the healthy population $[12,13], 16.8 \%$ in patients with rheumatoid arthritis [14], and $25.9 \%$ in the central nervous system [15]. Further studies in Iran shows the prevalence of JCV in renal transplant receivers is $43 \%$ [16].

Because of the clinical importance of BKV and JCV in immunocompromised patients, investigation of these viruses in renal transplant receivers is warranted. Our knowledge about the prevalence of JCV and BKV in the patients is limited in Iran, and for the first time, we report the prevalence of the viruses in the north of Iran. As a result, it was found that BKV and JCV were significantly prevalent in renal transplant recipients than healthy controls.

\section{Materials and Methods}

\section{Sample Collection}

In this study, 91 urine samples were collected from renal transplant recipients admitted to the 5th Azar Hospital in Gorgan, Iran. Further 65 urine samples were also obtained from healthy controls with no history of renal transplant or usage of immunosuppressants. No pregnant women were included in the study. The samples were stored at $-20^{\circ} \mathrm{C}$ until DNA extraction.

\section{Experimental Ethics}

An informed consent was obtained from the participants. This study was also approved by the Ethical Committee, Golestan University of Medical Sciences, Gorgan, Iran, with the approval code of IR.GOUMS.REC.1395.12.

\section{DNA Extraction}

The extraction of viral DNA from urine specimens was conducted by using a KiaSpin viral nucleic acid kit (KIAGEN, Tehran, Iran) according to the manufacture's protocol. The quality of extracted DNA was evaluated by the a DeNovix spectrophotometer (DeNovix, Inc., Wilmington, DE, USA). The 260/280 Optical density (OD) of 1.8-2 was considered as an ideal purity.

\section{Detection of BKV and JCV}

The primer that is complementary to the AgT coding sequence of the BK and JC polyomaviruses is shown in Table 1. PCR was performed in a final volume of $25 \mu \mathrm{L}$ containing $5 \mu \mathrm{L}$ sample, $2 \mu \mathrm{L}$ $10 \times$ PCR buffer, $2 \mu \mathrm{L} \mathrm{MgCl}_{2}, 1.5 \mu \mathrm{L}$ dNTP, 10 pmol of each forward and reverse primers, and 5 units/reaction Taq DNA polymerase.

The thermocycler (Peqlab Biotechnologie GmbH, Erlangen, Germany) protocol includes $94^{\circ} \mathrm{C}$ for $4 \mathrm{~min}$ and 34 cycles consisting of $94^{\circ} \mathrm{C}$ for $30 \mathrm{~s}, 55^{\circ} \mathrm{C}$ for $40 \mathrm{~s}$, and $72^{\circ} \mathrm{C}$ for $45 \mathrm{~s}$. A final $72^{\circ} \mathrm{C}$ step for 5 min was also included. The PCR products were observed in $1.5 \%$ agarose gel containing SYBR Safe stain (Invitrogen, Carlsbad, CA, USA). Subsequently, all positive samples were evaluated by 2 other BK- and JC-specific primers encompassing the VPC1 gene (Table 1).

For BK, the protocol consists of $5 \mu \mathrm{L}$ sample, $2 \mu \mathrm{L} 10 \times$ PCR buffer, $5 \mu \mathrm{L} \mathrm{MgCl}_{2}, 0.5 \mu \mathrm{L} \mathrm{dNTP}, 10 \mathrm{pmol}$ of each primer, 5 units/ reaction Taq polymerase in a final volume of $25 \mu \mathrm{L}$. The thermal condition was as follows: $95^{\circ} \mathrm{C}$ for $5 \mathrm{~min}$, amplification was performed in 35 cycles composed of $95^{\circ} \mathrm{C}$ for $45 \mathrm{~s}, 59^{\circ} \mathrm{C}$ for $45 \mathrm{~s}$, and $72^{\circ} \mathrm{C}$ for $60 \mathrm{~s}$. A final $72^{\circ} \mathrm{C}$ extension step was conducted for 10 $\min$.

The same concentrations were used for amplifying the JCV. However, thermocycler conditions include $94^{\circ} \mathrm{C}$ for $5 \mathrm{~min}$, followed by 35 cycles consisting of $94^{\circ} \mathrm{C}$ for $60 \mathrm{~s}, 55^{\circ} \mathrm{C}$ for $60 \mathrm{~s}$, and $72^{\circ} \mathrm{C}$ for $60 \mathrm{~s}$, as well as a final $72^{\circ} \mathrm{C}$ step for $5 \mathrm{~min}$. PCR-positive products were sent for direct sequencing (Macrogen, Seou, South Korea).

\section{Genotyping}

PCR products of BKV and JCV at the VP1 region were sequenced (Macrogen, Seou, South Korea). Results of sequencing were double-checked by eye and Bioedit software package [17] for quality and validity of the data. For multiple sequence alignment, MUSCLE was used in the setting of the CLC sequence viewer software tool [18]. The alignment was performed on the sequenced VP region of BKV and JCV versus all known genotypes of these vi- 
Table 1. BKV- and JCV-specific primers and their respective products

\begin{tabular}{lllc}
\hline Primer & $\begin{array}{l}\text { Amplifying } \\
\text { region }\end{array}$ & $5^{\prime}-3^{\prime}$ sequence & $\begin{array}{c}\text { Product } \\
\text { size, bp }\end{array}$ \\
\hline PEP & AgT & $\begin{array}{l}\text { AGTCTTTAGGGTCTTCTAC } \\
\text { GGTGCCACCTATGGAACAG }\end{array}$ & 172 \\
\hline BKV & VP1 (JCV) & $\begin{array}{l}\text { GTACTATAACCCCTAAAAACC } \\
\text { ATGTACAATAAAAGCACCTG }\end{array}$ & 584 \\
\hline JCV & VP1 (BKV) & $\begin{array}{l}\text { AGAAAAGGAGAAAGGAAGGACCC } \\
\text { TCTGTAATTGAGTCAACCCCAGTTT }\end{array}$ & 101 \\
\hline
\end{tabular}

JCV, John Cunningham virus; BKV, BK virus.

Table 2. Distribution of BKV and JCV based on gender within the case and control groups

\begin{tabular}{|c|c|c|c|c|c|c|c|c|}
\hline $\mathrm{BKV}^{\mathrm{a}}$ & $\mathrm{JCV}$ & \multicolumn{2}{|l|}{ female } & $\begin{array}{l}\text { female total, } \\
\%(n)\end{array}$ & \multicolumn{2}{|l|}{ male } & $\begin{array}{l}\text { male total, } \\
\%(n)\end{array}$ & $\begin{array}{l}\text { grand total, } \\
\%(n)\end{array}$ \\
\hline $\mathrm{P}$ & $\mathrm{N}$ & $1.282(2)$ & 0.00 & $1.28(2)$ & $3.85(6)$ & 0.00 & $3.85(6)$ & $5.13(8)$ \\
\hline \multirow[t]{2}{*}{$\mathrm{N}$} & $\mathrm{N}$ & $8.33(13)$ & $12.18(19)$ & $20.51(32)$ & $33.33(52)$ & $26.28(41)$ & $59.62(93)$ & $80.13(125)$ \\
\hline & $\mathrm{P}$ & $3.21(5)$ & 0.00 & $3.21(5)$ & $4.49(7)$ & $3.21(5)$ & $7.69(12)$ & $10.90(17)$ \\
\hline $\mathrm{N}$ total & & $11.54(18)$ & $12.18(19)$ & $23.72(37)$ & $37.82(59)$ & $29.49(46)$ & $67.31(105)$ & 91.03 (142) \\
\hline Grand total & & $13.46(21)$ & $12.18(19)$ & $25.64(40)$ & $44.87(70)$ & $29.49(46)$ & $74.36(116)$ & 100.00 \\
\hline
\end{tabular}

JCV, John Cunningham virus; BKV, BK virus. ${ }^{a}$ Positive, $\mathrm{P}$ and Negative, $\mathrm{N}$.

ruses. A phylogenetic tree was constructed for the representation of distance-relationship of the data to other genotypes. The phylogenetic trees were constructed with the neighbor-joining algorithm within the CLC software package. Bootstrap 1000 was utilized for topological validation of the trees.

\section{Statistical Analysis}

Statistical analysis is performed by SPSS software version 16 . The difference in the relative distribution between the groups is carried out by $\chi^{2}$ tests, with a confidence interval of $95 \%$. A $p$ value $<0.05$ was considered as significant.

\section{Results}

In this study, 91 urine samples were obtained from immunosuppressed renal transplant receivers (70 male and 21 female cases) with a mean age of $39.78 \pm 11.19$ years.
Additional sex- and age-matched control groups consisting of 65 participants were also included. The mean age of the control group (46 male and 19 female cases) was $40.32 \pm 10.7$ years. Table 2 shows the demographical data. The average duration of hemodialysis in the case group was $58.96 \pm 50.77(1-180)$ months.

As a result, the frequency of the BKV in this case-control cohort study was $15.38 \%$ (14/91), including 3 female and 11 male cases. The frequency of JCV was $19.78 \%$ (6 in female and 12 in male cases). In the control group, the genome of the BKV was not observed, while the JCV was detected in $7.69 \%(5 / 65)$, and all of them were males. The prevalence of BKV between the case and control groups was significant $(p<0.0001)$. JCV was also significantly higher in the case group $(p=0.028)$. There was no significant association between BKV and JCV and the age or duration of dialysis $(p>0.05)$. 


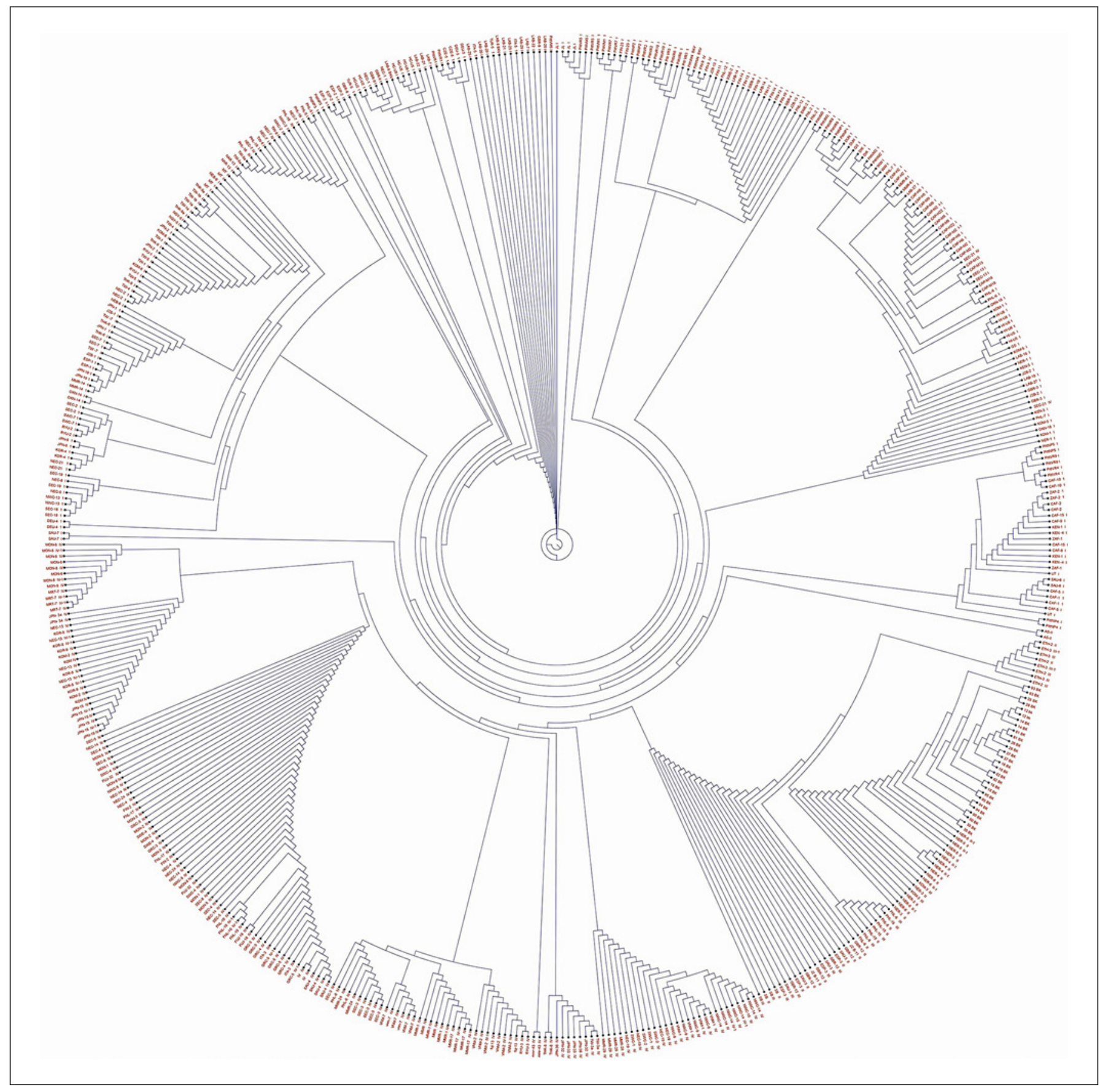

Fig. 1. Phylogenetic tree demonstrating VP1 sequence of BKV. Data show BKVs (those with digits left to the $\mathrm{BKV}$ ) have a close distance to genotype II. BKV, BK virus.

The phylogenetic study for determination of the dominant genotype in the north of Iran has revealed that all sequenced BKV VP1 belonged to genotype II (Fig. 1). Furthermore, of 23 sequenced VP1 for JCV-positive PCR products, all were genotype I (Fig. 2).

\section{Discussion}

Polyomaviruses are involved in different human abnormalities, including Merkel cell carcinoma [19] and renal cell carcinoma [20]. Investigating BKV reactivation 


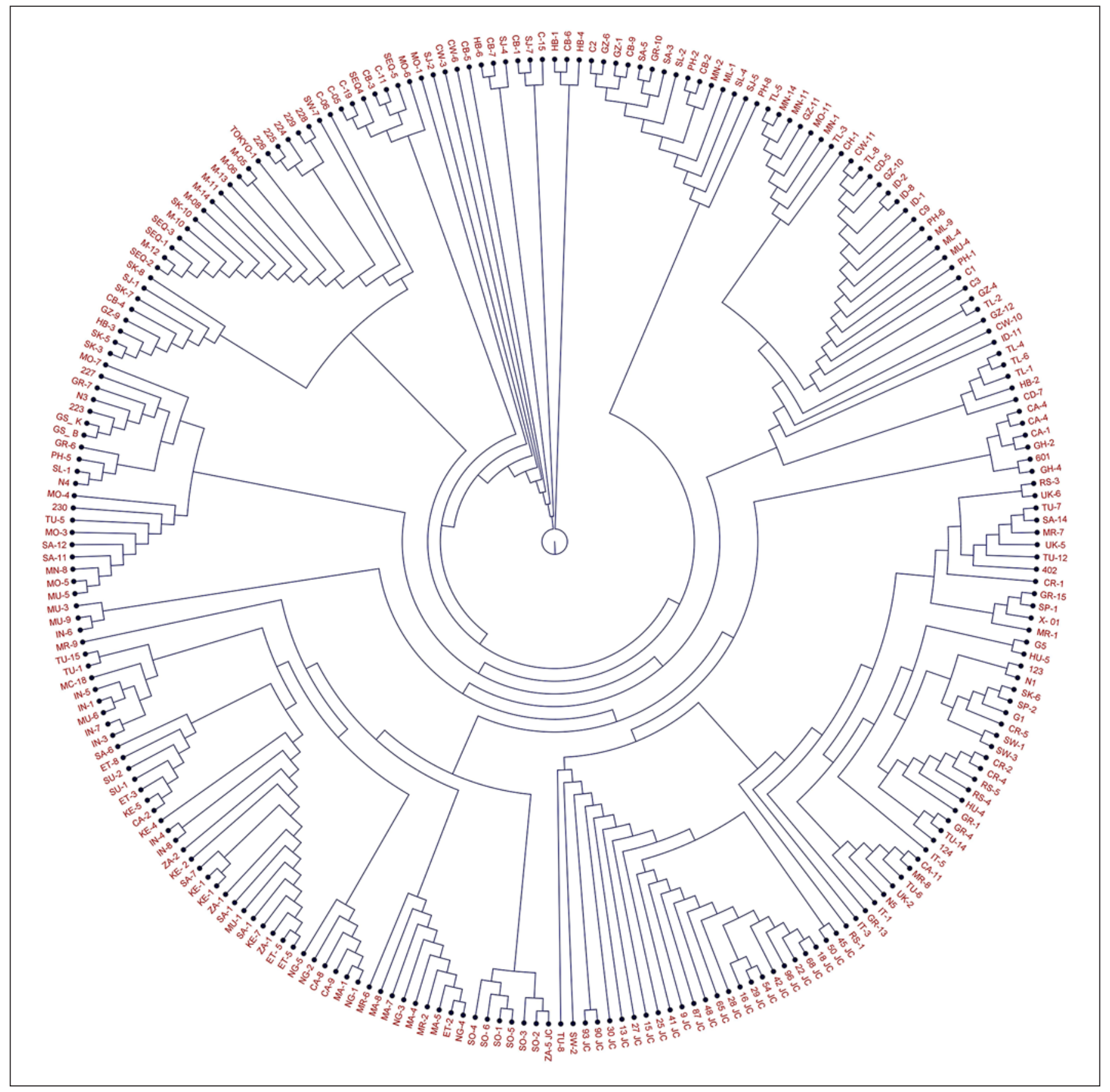

Fig. 2. Phylogenetic tree demonstrating VP1 sequence of JCV. As illustrated, JCVs (those with digits left to the JCV) have a close distance to those JCV s belonging to genotype I. JCV, John Cunningham virus.

among renal transplant recipients is of great importance as it can cause nephropathy followed by the rejection of allograft. In the present study, for the first time, the prevalence of BKV and JCV is reported in 2 case and control groups in the north of Iran. Previous works have been reported a $\sim 29 \%$ BKV prevalence in renal transplant receivers [6-9]. On the other hand, reports on JCV in renal transplant receivers in Iran are limited to few studies. In that case, the prevalence of JCV in renal transplant receivers is almost $29.5 \%$ [12-16]. In the immunosuppressed 
Table 3. Summary reports of prevalence of BKV and JCV from different parts of Iran

\begin{tabular}{|c|c|c|c|c|c|c|c|c|c|}
\hline Atyabi et al. [12] & Case-control & Isfahan & $\begin{array}{l}\text { Traditional PCR/ } \\
\text { sequencing }\end{array}$ & 143 & 100 & $51(35.66)$ & $7(7)$ & - & - \\
\hline Kaydani et al. [9] & Cross-sectional & Ahvaz & PCR-RFLP & 122 & - & - & - & $51(41.8)$ & - \\
\hline Pakfetrat et al. [21] & Cross-sectional & Shiraz & qRT-PCR & 108 & - & - & - & $17(15.7)$ & - \\
\hline Tajedin et al. [22] & Cross-sectional & Isfahan & PCR-RFLP & 220 & - & - & - & $102(75)$ & - \\
\hline Samarbasf Zadeh [7] & Cross-sectional & Ahvaz & $\begin{array}{l}\text { Double PCR and } \\
\text { semi-nested-PCR }\end{array}$ & 78 & - & - & - & $5(6.8)$ & - \\
\hline Ghafari et al. [6] & Cross-sectional & Urmia & $\begin{array}{l}\text { Immuno- } \\
\text { histochemistry }\end{array}$ & 160 & - & - & - & $21(13)$ & - \\
\hline
\end{tabular}

JCV, John Cunningham virus; BKV, BK virus.

transplant receivers, the rate of JCV is almost $38 \%[16$, 19-21].

As a result, we found $15.38 \%$ (14/91) of total patients were BKV positive, of which 3 cases were female and 11 cases were male. Meanwhile, the genome of JCV has been observed in $19.78 \%$ (18/91) of cases, including 6 female and 12 male cases. In the healthy control group, the prevalence of BKV was zero, while JCV was detected in 5 male cases. The results show a lower prevalence of BKV and $\mathrm{JCV}$ in renal transplant receivers in the north of Iran. Further reports of BKV and JCV prevalence in Iran are summarized in Table 3.

In previous studies, the rate of BKV prevalence is reported from $0 \%$ in the study of [20] to $62 \%$ in the study of [22]. In later research, the genome of BKV was detected in 136/220 urine samples by using the PCR technique. However, the result of the present study is consistent with that of Pakfetrat et al. [21], which was conducted in the center of Iran. Further epidemiological data are reported in [24]. This difference of detection may be attributed to the time of sampling, age of examination [24], and design of the study, for example, Pezeshgi et al. [23] have screened both BKV and JCV during 1 year after renal transplantation, and no sign of new cases was observed. The preva- lence of JCV in the present study (19.78\%) was lower than that reported from previous studies in Iran (31\%). JCV is known to cause progressive multifocal leukoencephalopathy, which has been reported in the renal transplant population [25]. Screening of JCV is not a routine test for renal transplantation.

It was also evaluated if there is any association between BKV or JCV and age or duration of hemodialysis. Accordingly, no significant association was observed between BKV or JCV with age or duration of dialysis $(p>$ $0.05)$. This finding is consistent with that in Taheri et al. [4].

According to molecular and serological studies, BKVs are divided into 4 genotypes: I, II, III, and IV. Genotype I is prevalent worldwide, while genotype IV is more prevalent in Asia, and II/III are less frequent [26]. Furthermore, 18 different genotypes of JCV are detected all around the world. Genotype Af2 is dominant in Africa and the south of Asia. Besides, genotypes SC, CY, MY, B2, B1-d, B1-b, and B1-a are frequent in Eastern Asia [27-29]. Our data clearly show that genotype II of BKV and genotype I of JCV are prevalent among renal transplant recipients in the north of Iran. There are not many studies in Iran reflecting dominant genotypes of poly- 
omaviruses. However, in one study performed by Tajedini et al. [22] on 220 patients, genotype I (46.36\%) was more frequent than genotype II (3.2\%), genotype III (2.27\%), and genotype IV (10\%). Kaydani et al. [9] have found that genotype I (39.34\%) and genotype III (2.46\%) were 2 dominant genotypes among 122 patients [22]. In another study by Motazakker et al. [8] on 120 urine samples from renal transplant recipients, genotype I (10\%) was prevalent. There are few studies on the prevalence of JCV among healthy and transplant recipients. Atabi et al. [16] have found JCV among patients (43\%) and healthy people (7\%). Further evidence of JCV infection among renal transplant recipients is from the studies of Pezeshki and Ghods [21] and Bozorgi et al. [13] on urine samples from 31 patients and 133 healthy controls, respectively. The frequency of the JCV in these studies has been 22.58 and $38.35 \%$, respectively. Unfortunately, no evidence of JCV genotype is known in Iran, and for the first time, we report that the JCV genotype I is dominant in the north of Iran. Further investigation is warranted to develop our knowledge about the distribution of JCV and BKV in Iran.

One of the important disadvantages of the present study is that the load of BKV and JCV is not evaluated. Hence, it cannot be concluded that the positive cases are active viral infections or are resulted from quasi-species. Therefore, it is warranted that more sensitive and quantitative methods like RT-PCR be used for investigation of $\mathrm{BKV}$ and JCV in renal transplant recipients in the north of Iran.

\section{Conclusion}

The results obtained here show a relatively lower prevalence of BKV and JCV in immunocompromised renal transplant receivers and healthy controls than that reported from Iran. Additionally, it was found that geno- type II of BKV and genotype I of JCV are prevalent among renal transplant recipients in the north of Iran. It was for the first time we report the JCV genotype in this country.

\section{Acknowledgements}

All authors contributed to this study are acknowledged. We thank the Department of Microbiology, School of Medicine, Golestan University of Medical Sciences, Gorgan, Iran, and its great staff for their financial support and purchasing us non-open access articles.

\section{Statement of Ethics}

This study is approved by the Ethical Committee, Golestan University of Medical Sciences, Gorgan, Iran, with the approval code of IR.GOUMS.REC.1395.12.

\section{Conflict of Interest Statement}

Authors have nothing to declare.

\section{Funding Sources}

This work performed as a master of science degree program of Fereshteh Safaei and fully granted by the Golestan University of Medical Sciences, Gorgan, Iran.

\section{Author Contributions}

Substantial contributions to the conception or design of the work; or the acquisition, analysis, or interpretation of data for the work: F.S., M.H., A.T., A.M., and H.R.N. Drafting the work or revising it critically for important intellectual content: F.S., A.M., and M.H. Final approval of the version to be published: A.T. and A.M. Agreement to be accountable for all aspects of the work in ensuring that questions related to the accuracy or integrity of any part of the work are appropriately investigated and resolved: all the authors.

\section{References}

1 Moens U, Krumbholz A, Ehlers B, Zell R, Johne $\mathrm{R}$, Calvignac-Spencer $\mathrm{S}$, et al. Biology, evolution, and medical importance of polyomaviruses: an update. Infect Genet Evol. 2017;54:18.

2 Behzad-Behbahani A, Klapper PE, Vallely PJ, Cleator GM, Khoo SH. Detection of BK virus and JC virus DNA in urine samples from immunocompromised (HIV-infected) and immunocompetent (HIV-non-infected) patients using polymerase chain reaction and microplate hybridisation. J Clin Virol. 2004;29(4):224-9.
3 Gossai A, Waterboer T, Nelson HH, Michel A, Willhauck-Fleckenstein M, Farzan SF, et al. Seroepidemiology of human polyomaviruses in a US population. Am J Epidemiol. 2016;183(1):61-9.

4 Taheri S, Kafilzadeh F, Shafa M, Yaran M, Mortazavi M, Seirafian S, et al. Comparison of polyomavirus (BK virus and JC viruses) viruria in renal transplant recipients with and without kidney dysfunction. J Res Med Sci. 2011;16(7):916-22.
5 Gardner SD, Field AM, Coleman DV, Hulme B. New human papovavirus (B.K.) isolated from urine after renal transplantation. Lancet. $1971 ; 1(7712): 1253-7$.

6 Ghafari A, Lessan-Pezeshki M, Taghizadieh M, Rahimi E. BK polyoma virus nephropathy among Iranian renal transplant recipients. Transplant Proc. 2008;40(1):193-5. 
7 Samarbasf Zadeh AR, Makvandi M, Kayedani GA, Shahbazian H, Poorfarziani V, Yaghoobi $\mathrm{R}$, et al. Prevalence of $\mathrm{BK}$ virus in renal allograft recipients pre and post transplantation in Iran. Jundishapur J Microbiol. 2009; 2(2):47-52.

8 Motazakker M, Bagheri M, Imani M. Subtyping of BK virus in Iranian Turkish renal transplant recipients by RFLP-PCR. Maedica. 2012 Jan;7(1):10-3.

9 Kaydani GA, Makvandi M, Samarbafzadeh A, Shahbazian H, Hamidi Fard M. Prevalence and distribution of $\mathrm{BK}$ virus subtypes in renal transplant recipients referred to Golestan hospital in Ahvaz, Iran. Jundishapur J Microbiol. 2015;8(3):e16738.

10 Maginnis MS, Atwood WJ. JC virus: an oncogenic virus in animals and humans? Semin Cancer Biol. 2009;19(4):261-9.

11 Tan CS, Koralnik IJ. Progressive multifocal leukoencephalopathy and other disorders caused by JC virus: clinical features and pathogenesis. Lancet Neurol. 2010;9(4):70040-5.

12 Atyabi SR, Bouzari M. Age related evaluation of urinary excretion of JC virus in non-immunocompromised individuals in Isfahan. 2015.

13 Bozorgi SM, Tahaei SM, Mohebbi SR, Sahba N, Damavand B, Romani S, et al. Molecular prevalence of JC virus in Tehran, Iran. Gastroenterol Hepatol Bed Bench. 2012;5(2):8489.

14 Atyabi SR, Bouzari M. Frequency of JC virus in rheumatoid arthritis patients in Isfahan, Iran. 2015.
15 Sadeghi F, Salehi-Vaziri M, Ghodsi SM, Alizadeh A, Bokharaei-Salim F, Saroukalaei ST, et al. Prevalence of JC polyomavirus large $\mathrm{T}$ antigen sequences among Iranian patients with central nervous system tumors. Arch Virol. 2015;160(1):61-8.

16 Atyabi SR, Bouzari M, Kardi MT. John cunningham (JC) virus genotypes in kidney transplant recipients, rheumatoid arthritis patients and healthy individuals in Isfahan, Iran. J Med Virol. 2017;89(2):337-44.

17 Hall TA. BioEdit: a user-friendly biological sequence alignment editor and analysis program for Windows 95/98/NT. Nucleic Acids Symp Ser. 1999;41:95-8.

18 Knudsen B, Knudsen T, Flensborg M, Sandmann $\mathrm{H}$, Heltzen $\mathrm{M}$, Andersen A, et al. Clc sequence viewer. A/S Cb, version. 2011;6(2).

19 Vahabpour R, Aghasadeghi MR, Salehi-Vaziri M, Mohajel N, Keyvani H, Nasimi M, et al. Prevalence of Merkel cell polyomavirus in Tehran: an age-specific serological study. Iran Red Crescent Med J. 2016;18(5):e26097.

20 Jozpanahi M, Ramezani A, Ossareh S, Banifazl M, Bavand A, Mamishi S, et al. BK viremia among Iranian Renal transplant candidates. Iran J Pathol. 2016;11(3):210.

21 Pakfetrat M, Yaghobi R, Salmanpoor Z, Roozbeh J, Torabinezhad S, Kadkhodaei S. Frequency of polyomavirus BK infection in kidney transplant patients suspected to nephropathy. Int J organ Transplant Med. 2015;6(2): 77.

22 Tajedin N, Shanehsazzadeh M, Ghandehari F. Monitoring subtypes of the human polyomavirus $\mathrm{BK}$ in Iranian adult kidney transplant patients. 2013;3:315-19.
23 Pezeshgi A, Ghods A, Keivani H, Asgari M, Shatty M. Incidence of BK virus nephropathy $(\mathrm{BKVN})$ in renal transplant recipients. Int $\mathrm{J}$ Organ Transplant Med. 2012;3(3):115-8.

24 Reploeg MD, Storch GA, Clifford DB. BK virus: a clinical review. Clin Infect Dis. 2001; 33(2):191-202.

25 Drachenberg CB, Hirsch HH, Papadimitriou JC, Gosert R, Wali RK, Munivenkatappa R, et al. Polyomavirus BK versus JC replication and nephropathy in renal transplant recipients: a prospective evaluation. Transplantation. 2007;84(3):323-30

26 Zhong S, Randhawa PS, Ikegaya H, Chen Q, Zheng HY, Suzuki M, et al. Distribution patterns of BK polyomavirus (BKV) subtypes and subgroups in American, European and Asian populations suggest co-migration of BKV and the human race. J Gen Virol. 2009; 90(Pt 1):144-52.

27 Guo J, Sugimoto C, Kitamura T, Ebihara H, Kato A, Guo Z, et al. Four geographically distinct genotypes of JC virus are prevalent in China and Mongolia: Implications for the racial composition of modern China. J Gen Virol. 1998;79(Pt 10):2499-505.

28 Sugimoto C, Kitamura T, Guo J, Al-Ahdal MN, Shchelkunov SN, Otova B, et al. Typing of urinary JC virus DNA offers a novel means of tracing human migrations. Proc Natl Acad Sci U S A. 1997;94(17):9191-6.

29 Yogo Y, Sugimoto C, Zheng H-Y, Ikegaya H, Takasaka T, Kitamura T. JC virus genotyping offers a new paradigm in the study of human populations. Rev Med Virol. 2004;14(3):17991. 